\section{Antropologia poética da comunicação: esse ancestral homem moderno ${ }^{1}$}

Resumo

0 universo cultural de nossas civilizações se desencantou e, só na poesia a natureza continua povoada de almas e sujeita a metamorfoses.

\section{Abstract}

The disenchantment of the cultural universe of our civilization has shown that only in the realm of poetry can nature continue to be settled by souls and to be submitted to metamorphoses.

Maria da Conceição Xavier de Almeida

UFRN
"A compreensão do mito talvez tivesse salvo Lúcio. Mas quem iria falar em mito? O científico seria a lobotomia. A luta entre deuses e titãs foi reduzida a uma luta entre gato e rato."

Nise da Silveira

Como na metáfora da CAVERnA de Platão, onde luz e trevas se mesclam na projeção da sombra, há que se tomar o enunciado acima como uma imagem carregada de fragmentos de sentido; um enunciado aberto, parcial. Uma meia-verdade.

Se é razoável afirmar que o mundo das tecnicidades declarou guerra ao mito, é, no mínimo, aconselhável vasculhar os porões desse ancestral homem moderno, para observar mais que explicar, compreender mais que traduzir os dispositivos a um só tempo mito/lógicos que presidem a estrutura do simbólico, da cultura e da história humana - ontem, hoje e amanhã. As reflexões que surgiram aqui nada mais são que combinações, reformatações, recortes, por vezes certamente mutilações e deformações, do estoque de idéias de pensadores contemporâneos que, visceralmente impregnados de seu tempo, abriram mão dos pertencimentos históricos patologizantes que dissolvem 0 homem na sincronia da cultura e limitam o conhecimento ao artifício de traduções datadas. Muitos fantasmas me visitaram na escritura dessa comunicação, mas sobretudo Joseph Campbell, Claude LéviStrauss, Edgar Morin, Nise da Silveira e Gilles Deleuze povoaram a minha solidão quando me pus a pensar a permanência do dispositivo mítico. Viajei com esses autores. Como duendes, eles me contaminaram do necessário medo, diria mesmo, do pavor, das idéias justas, que, conforme provocação de Deleuze, "são sempre aquelas idéias conforme as significações dominantes ou as palavras de ordem 
estabelecidas"2.

A idéia justa talvez seja aquela que encarcera o mito nas configurações societais denominadas tribais, primitivas, selvagens. A idéia justa toma o enunciado mítico como um ensaio, um estágio incipiente do pensamento; uma linguagem ainda débil, uma prefiguração arquetipal, mas incompleta, do dispositivo científico. A idéia justa cadastra o mito conforme a hierarquia simplificadora do paradigma ocidental e reduz a uma linguagem da negatividade e da ausência. O mito seria, assim, uma fabulação sem sentido, a negação do tempo, a supressão da história, o embotamento das contradições e conflitos sociais. A pergunta a ser feita é: de que sentido, tempo e história estamos a falar? Será o ideário científico assim tão narcísico, intransigente e reacionário que não permite a enunciação de outras histórias, tempos e sentidos que não os nossos?

Não me ponho aqui ao exercício de responder a uma tal pergunta, nem de sistematizar ensaios - alguns já consagrados, outros ainda em construção - que tangenciam a problemática da força do paradigma. Ao invés disso, expresso meu estranhamento e desacordo com as idéias justas do nosso tempo que, em sua expressão máxima, separou o homem do resto do mundo, opôs a natureza à cultura, cindiu a harmonia conflitante da ordem/desordem, fraturou a dialógica cérebro/espírito, corpo/alma. Imaginando um homem sem imaginação, o grande paradigma do ocidente embruteceu a razão, sacralizou-a, transformou-a em mito.

Para fazer jus a esse ideário, para tornar operacional essa fabulação, o mundo moderno se armou até os dentes. Um arsenal normativo de poder, inibidor da pulsão criadora, cerceador das liberdades, intransigente com o múltiplo e com o diverso, tirano com o desvio, instalou-se nos corpos, nas almas, no aparelho de Estado, nas escolas, nas ruas, campos, construções.

Por que tanta trincheira, guerra de guerrilha, portuário de classificações intermináveis, capacetes, cacetetes, antidistônicos, palavras de ordem, ordem do dia? Contra quem e contra o que estamos em guerra? Por que tanta armação? Será mesmo esse hóspede indesejável pela cultural Aldol, tão forte? Parece que sim! Ele é impossível!!! como aquele menino que joga a biloca na vidraça da velha ranzinza!

Ora, quase tudo nos leva a crer que essa luta é inglória. Há, parece, uma parte insubmissa, uma potência criadora, um dispositivo do pensamento pouco afeito às conformações historicizantes. Há um sentimento de dor inscrito no conceito. Retorno às palavras iniciais desse texto, para repensar o desencantamento. $\mathrm{Na}$ verdade, o universo de nossas civilizações lutou para se desencantar. Mas, ao dissolver as antigas mitologias, a história contemporânea recolhe, da polifonia social, novos materiais a partir dos quais regenera, num estilo propriamente moderno, o pensamento simbólico/mitológico/ mágico. Apesar de desfeita a ancestral analogia antropo-sócio-cósmica, a forma paradigmática que Ihe dava sustentação continua viva nas nossas experiências afetivas, na poesia, na psicanálise, nas religiões, nas idéias de salvação, progresso e Estado-nação, ao mesmo tempo em que contamina a razão e a ciência.

Um tal enunciado sugere o alerta contra a simplificação das interpretações que cindem a organização complexa, digo, a um só tempo mito/lógica das idéias, da cultura e da história. Mais que isto, reativa os circuitos de uma memória sóciohistórica. Mais que isto, reativa os circuitos de uma memória sócio-histórica, repondo as combinações mutantes entre mito e racionalidades. Possibilita a compreensão de que o pensamento mitológico evoluiu, deslocou-se, transformou-se e produziu neomitos que se fixam em idéias. Assim, o neomito, forma historicizada do estilo mítico, espiritualiza e diviniza uma idéia a partir de seu núcleo interior. Sem retirar 
o sentido racional da idéia que parasita, o neomito imprime aí uma sobrecarga de sentido que, por vezes, transforma a idéia.

A pergunta é, então: o nosso século está realmente menos mitificado que os chamados tempos míticos? - Respondo negativamente, mas devo precisar que acepção de mito estou a falar.

Aqui, deixo de lado o mito enquanto um enunciado, uma forma de linguagem, um recurso imagético de expressão da cultura codificada. O meu caminho é outro. Nem mais, nem menos importante, apenas outro caminho, no qual me movo de forma... não mais familiar, mas de um jeito mais faceiro, vagabundo.

Tomo o mito como um itinerário do pensamento (E. Morin), como uma estratégia de ver/pensar o mundo (C. Lévi-Strauss), como um modo de pensar do homem (Cassirer). O dispositivo mítico é pois, assim, um estilo do pensamento humano.

Como itinerário/estratégia/estilo, o pensamento mítico tece conjuntamente o simbólico, o imaginário e eventualmente o real. Pulsão sobretudo criadora e liberta das cronologias e temporalidades paradigmatizadas, a expressão mítica responde pelo artifício de ordenação, reordenação e deformação simbólica da história humana. O mito obedece a uma lei polilógica fundada no paradigma da unidualidade que institui a um só tempo a identidade e a realidade. O mito é o "coagulum" do sentido. Como um jogo simbólico e imaginal, esse estilo de pensar comporta uma proliferação semântica e um excesso de significações que, em muito, transcende a objetivação das expressões culturais.

Resistindo a conceitualizações impostas pelo pensamento racional, a construção mítica responde pelo processo fundamental de projeção/ identificação humana. Sem foco preciso, as imagens míticas encadeiam seqüências acontecimentais, quer históricas, quer imaginárias, quer as duas ao mesmo tempo, como na expressão lendária e na literatura funcional. Refaz a unidade entre a busca e a experiência do sentido. Superpõe planos, dimensões. Abre as identidades à polifonia arquetipal que dissolve o herói no anti-heróico e vice-versa; vagabundeia nas encruzilhadas entre o real e o ideal; funde mundos opostos; culturaliza a natureza e imprimi-lhe subjetividade ao fabular a história animal e vegetal; antropomorfiza o universo e imprime ao homem caracteres cosmológicos. Portador de uma capacidade sintética por excelência, o dispositivo mítico desterritorializa, define e reordena o estoque simbólico da construção humana. "O mito é a máquina de supressão do tempo", sugere C. Lévi-Strauss.

Mas nem só de mito vive o Homem...

Bem vistas as coisas, ao estilo mítico de pensar corresponde um outro: o lógico/ racional. $E$, se é plausível afirmar que nenhuma comunidade humana sobrevive sem o cimento mitológico, é igualmente inconteste que, das civilizações arcaicas às modernas, o ingrediente empírico/técnico/ racional tem tecido, conjuntamente com o dispositivo mítico, a história errante do homem no planeta Terra.

A produção da cultura e da história, numa palavra, a condição humana, é parasitada pela unidualidade do pensamento. O homem é um animal mitológico, produto e produtor da dialógica entre duas estratégias, dois modos de decodificação do mundo. "Os dois modos coexistem, entreajudam-se, estão em constantes interações como se tivessem uma necessidade permanente um do outro; podem por vezes confundir-se, mas sempre provisoriamente. Toda renúncia ao crescimento empírico/técnico/racional conduzia os humanos à morte; toda a renúncia às suas crenças fundamentais desintegraria a sua sociedade." 3

É possível, sim, falar da permanência do mito como um recurso imagético do 
pensamento humano universal, a-histórico, antropológico. Se nos distanciamos da desconfiança impressa pelas configurações endurecidas das significações datadas, se não nos deixamos embrutecer pelos códigos, pela tirania da palavra, pela cegueira da racionalização; se concordamos com Deleuze e Guattari que "o conceito de um pássaro não está em seu gênero ou em sua espécie, mas na composição de suas posturas, de suas cores e de seus cantos" 4 , ou com Bachelard que "não se inventam idéias sem retificar um passado"5; se exercitamos outras formas de ver o mundo, uma vez que "mudar de método, às vezes, é se dar uma chance suplementar de se instruir" 6 ; talvez possamos decifrar, contemplar e conviver com esse ancestral homem moderno que somos nós.

Não há, parece, um paradigma do homem arcaico e um paradigma do homem moderno. Se ontem a distinção empírico/ técnico/racional e simbólico/mitológico/ mágico não se constituía em dois pólos separados, mas num universo duplo, unidual, também hoje, sob um manto de um deus ciumento que desclassificou todos os outros, ao lado de uma razão narcísica que expurgou a imagem, a poética e a fantasia (ao domesticar a pulsão imaginal criadora), o paradigma enigmático do homem unidual permanece. Nas palavras de Edgar Morin, "o problema dos dois pensamentos não é, portanto, um problema original, e um problema histórico ultrapassado; é um problema de todas as civilizações, inclusive contemporâneas: é um problema antropossocial fundamental"7.

Daí por que fica sem sentido afirmar a polarização dos dois estilos de pensamento que presidem a odisséia humana. Assim como cada lado de um mesmo rosto não configura isoladamente um rosto, a negação de um dos dois pensamentos dissolve o homem no reino da fabulação ou no reino da materialidade. Os dois estilos de leitura do mundo são carentes um do outro: o pensamento mítico é carenciado se não ascender à objetividade; e o racional é carenciado se for cego para a subjetividade; o mythus alimenta mas confunde o pensamento; o logos não consegue vencer o obstáculo da contradição. É necessário, pois, entender as relações de antagonismo e complementaridade entre os movimentos distintos do pensamento humano. Para tal, é igualmente necessário livrar-se da armadilha da clareza e da obscuridade excessivas; a primeira mata a verdade, a segunda a torna invisível.

O homem é, pois, um ser mitológico e, "quem quer que exerça os dois pensamentos, o empírico/técnico/racional e o simbólico/mitológico/mágico, vive muito naturalmente de uma maneira una e dúplice a consubstancialidade dos dois mundos diferentes". 8

\section{É hora de parar}

As palavras também cansam. Batalha difícil essa, do pensamento com as palavras! As que aqui entraram em cena estão cansadas - talvez pela consciência mesmo de ter mutilado ou deixado de lado tantos outros sentidos, segredos. Mas ainda há convidados a falar: devolvo a eles as últimas palavras.

O filósofo marinheiro Michel Serres parece estar a falar da sofrida separação entre mito e razão: "Então, cansado de sofrer, cada um abre os braços, como faziam outrora os suplicantes, e cada mão encontra uma mão a sua esquerda e outra a sua direita"9. Gaston Bachelard confessa: "Permaneci ávido por conhecer, cada vez em maior número, as construções conceituais e, como nunca, igualmente as belezas da imaginação poética (...), é preciso moderar ou é preciso exagerar? Rendo-me aos dois movimentos" 10. Deleuze chega também, não para falar, mas para fazer falar o mito que nos pergunta: "Mas o que você sabe de mim, uma vez que acredito no segredo - quer dizer, na potência do falso - mais do que 
nos relatos que revelam uma deplorável crença na exatidão e na verdade?" 11. Deleuze recolhe-se então à sua solidão de pensador errante, não sem antes balbuciar estas palavras finais: "Desde o começo do mundo, os mergulhadores do pensamento voltam à superfície com os olhos injetados de sangue" 12 .

\section{Notas}

1 Conferência apresentada na III Semana de Humanidades. Natal, 1994. Publicado In: Odisséia. Revista do Centro de Ciências Humanas, Letras e Artes da UFRN. N. 2 - 3. Natal: EDUFRN, mar/out, 1995.

2 Deleuze, G. Conversações. Rio de Janeiro: Editora 34, 1992.

3 Morin, E. O método III. O conhecimento do conhecimento/ 1. Portugal: Europa-américa, s.d.

4 Deleuze, G. e Guattari, F. O que é filosofia. Rio de Janeiro: Editora 34, 1992.

5 Bachelard, G. Fragmentos de uma poética do fogo. São Paulo: Brasiliense, 1990.

6 Bachelard, G. op. cit.

7 Morin, E. op. cit.

8 Morin, E. op. cit.

9 Serres, M. Filosofia mestiça - le tiersinstruit. Rio de Janeiro: Nova Fronteira, 1993.

10 Bachelard, G. op. cit.

11 Deleuze, G. op. cit.

12 Deleuze, G. op. cit 